\title{
Analysis of Ageing Processes of Semi-Crystalline Materials
}

\author{
ALEKSANDRA KALWIK ${ }^{1}$, PRZEMYSLAW POSTAWA ${ }^{1}$, MARCIN NABIALEK ${ }^{2 *}$ \\ ${ }^{1}$ Department of Technology and Automation, Faculty of Mechanical Engineering and Computer Science, Czestochowa \\ University of Technology, 19c Armii Krajowej Str., 42-200 Czestochowa, Poland \\ ${ }^{2}$ Institute of Physics, Faculty of Production Engineering and Materials Technology, Czestochowa University of Technology, \\ 19 Armii Krajowej Str., 42-200 Czestochowa, Poland
}

Abstract: The article presents the influence of accelerated UV ageing on the structural properties of selected polymer materials. In this study, 3 types of materials from a group of thermoplastics known as PP30T, PE, POM were used. The test samples were prepared by injection moulding. In turn, an accelerated UV ageing process $(600 \mathrm{~h})$ was carried out in the UV Test chamber with fluorescent lamps characterized by a wavelength of $313 \mathrm{~nm}$. Changes in the structure of the tested materials were observed by using an optical microscope. Measurements of gloss on the surface of primary samples that were exposed to UV rays were also taken. In addition, the structure of primary and aged samples was tested by differential scanning calorimetry (DSC). The conducted studies have demonstrated the impact of UV radiation on the changes in the surface layer of tested materials.

Keywords: UV ageing, microscopic examination, semi-crystalline materials, structural properties, differential scanning calorimetry

\section{Introduction}

Polymer materials are very widely used in the manufacturing of products in all industrial sectors. Their popularity is associated with a relatively low price, very good price-performance ratio and high availability, as well as significant possibilities of modification of physical and functional properties [1]. The disadvantages of using polymer materials include, among others, changes in their properties under the influence of physical and chemical factors occurring in the conditions in which they are used. These include i.a.: temperature of use, chemical agents and light radiation, particularly UV. An important element which enhances the physical and chemical agents' effect is the simultaneous deformation of the products of plastics during their use [2]. They significantly affect the degradation processes of polymers $[3 \div 11]$.

Degradation which is caused by physical factors is termed as the ageing of the polymers [12]. Understanding the impact of ageing on the change in physical properties, as well as the utility of polymeric materials is essential for the correct selection for given application and subsequent failurefree exploitation of elements made from them. Degradation contributes to the formation of irreversible or much less reversible changes in the structure and physical properties of polymer materials [13 $\div 15]$.

There are the following types of degradation:

- thermal degradation, which occurs under the influence of the increased operating temperature or its rapid changes during the use of products [16],

- chemical degradation, caused by the effect of chemical compounds,

- radiation degradation, which occurs under the impact of high-energy radiation,

- biodegradation, caused by the activity of microorganisms and enzymes on the structure of polymers,

- mechanodegradation occurring under the influence of the breakage of macromolecules as a result of exceeding the cohesion forces of the polymer moulded piece or its exploitation with a significant load,

- oxidative degradation, etc.

\footnotetext{
*email: nmarcell@wp.pl
} 
In natural conditions, most often with the interaction of different types of degradation with different intensities of the impact of degradation factors occurs, which example is simultaneous impact of atmospheric (chemical and thermal degradation) and mechanical factors (mechanodegradation) on stadium seats during their use [12, $17 \div 19]$. In turn, in this study, [32, 33], it was found that the effect of many factors at the same time enhances the degradation processes. In publications $[25,26]$ it was pointed out that polymeric materials are characterized by different resistance and behaviour during keeping in aggressive substances.

Photodegradation, which occurs as a result of exposure to ultraviolet radiation or the visible spectrum of white light on components, is one of the most common process found during use of products made from polymer materials. Absorption of UV / VIS rays in the material appears when the energy of the absorbed radiation is equal to, or greater than the energy of decomposition of selected bonds occurring in the polymer macromolecules. This process was described in detail in [18, 20, 21]. In turn, in papers $[28,29]$ the influence of UV ageing on changes in the structure of polymer materials was demonstrated, which have a significant impact on the exploitation of products made of these materials. Photodegradation can lead to the deterioration of strength properties (tensile or bending strength), colour changes, gloss of moulded products. Initially, this process mainly occurs on the surface of polymeric products, causing fogging or micro-cracks. Their presence has a destructive effect on the polymer since it allows the penetration of volatile substances, e.g.: oxygen and a liquid in the deeper layers of the material, which facilitates the intensification of the processes of chemical degradation [22]. In the paper [30] the influence of accelerated ageing on the surface layers of aged materials was demonstrated. UVA radiation can cause e.g.: yellowing of the material, fading or so-called chalking of the surface layer, which consequently changes the gloss of the surface. On the other hand, UV-B rays contribute to changes in physical properties, mainly tensile strength and impact strength [23]. Photodegradation can be delayed by adding photostabilisers to materials - UV absorbing agents, quenching excited states of atoms or bonding free radicals $[20,24]$. In the publication [31], it was shown that additives in the form of photostabilisers contribute to delaying the degradation processes.

Due to the increasing application of polymer materials in various industries, there is a need to test

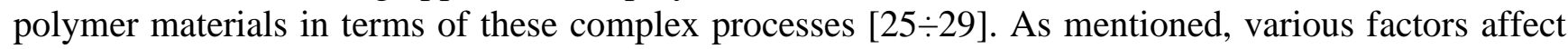
the polymeric materials during the use, whereby their interaction intensifies the degradation processes. Therefore, it is necessary to carry out research on the influence of the different conditions of their use and manufacturing methods and load condition on the process of degradation.

The aim of the research presented in the publication was to analyse the impact of accelerated UV ageing on changes in the structural properties of selected semi-crystalline materials.

\section{Materials and methods}

Materials from the thermoplastic group that were used in the research:

- $\quad$ poly (acetal) POM with the trade name ULTRAFORM POM 9,

- poly (propylene) with 30\% talc content PP30T with the trade name MOLPEN HP 500J,

- $\quad$ poly (ethylene) PE with the trade name HDPE 51090.

In addition, $2 \%$ of the masterbatch GRAFE was added for all materials with the exception of poly (acetal) on the carrier suitable for each material. The concentrates used were as follows: S6156-GR, S5152-GR. A suitable weight of the additives was weighed to an accuracy of $\pm 0.1 \mathrm{mg}$ using a Sartorius CP225 scale.

Before the production of test samples, all materials were prepared in accordance with the manufacturers' recommendations (temperature and drying time). Test specimens (rectangular type, and the A1 dumbbell-shaped) were performed using an injection moulding machine known as KraussMaffei KM65-160C4. Injection parameters are shown in Table 1. 
Table 1. Injection parameters of tested materials

\begin{tabular}{cccc}
\hline \multirow{2}{*}{ Parameter } & \multicolumn{3}{c}{ Material } \\
\cline { 2 - 4 } & POM & PP30T & PE \\
\hline Injection temperature, ${ }^{\circ} \mathrm{C}$ & 200 & 220 & 230 \\
\hline Injection speed, $\mathrm{mm} / \mathrm{s}$ & 40 & 60 & 60 \\
\hline Injection pressure, $\mathrm{MPa}$ & 100 & 100 & 100 \\
\hline Injection time, $\mathrm{s}$ & 0.52 & 0.62 & 0.58 \\
\hline Holding pressure, $\mathrm{MPa}$ & 50 & 50 & 50 \\
\hline Pressing time, $\mathrm{s}$ & 10 & 18 & 18 \\
\hline Cooling time, $\mathrm{s}$ & 20 & 20 & 20 \\
\hline
\end{tabular}

The places where microscopic observations were made were marked on the samples. The obtained specimens were then subjected to accelerated UV ageing in the ATLAS UV Test device. The total exposure time of the samples was $600 \mathrm{~h}$ and was divided into two cycles of $300 \mathrm{~h}$ for each. The prepared samples were installed before inserting the device in special frames.

The source of radiation came from eight fluorescent lamps with a wavelength of $313 \mathrm{~nm}$ UV-B. Before the beginning of the ageing process, as well as after every $200 \mathrm{~h}$ of working, the UV source was calibrated in order to maintain the repeatability of the dose affecting the tested samples. A radiation intensity of $0.89 \mathrm{~W} / \mathrm{m}^{2}$ was used. The temperature in the ageing chamber was $45^{\circ} \mathrm{C}$.

The intensity of solar radiation is measured in kLy (kilo Langley) - units used to measure sunlight. Subject-related literature data suggests that the average intensity of solar radiation in the region of Europe is $120 \mathrm{kLy} /$ year at a radiation intensity of $1.33 \mathrm{~W} / \mathrm{m}^{2}$, which corresponds to $100 \mathrm{~h}$ of ageing tests under laboratory conditions. At the assumed radiation intensity of $0.89 \mathrm{~W} / \mathrm{m}^{2}$, the total test time was 600 hours, which is equivalent to 4 years of ageing in natural conditions.

To observe the changes occurring on the surface of the samples subjected to irradiation the Keyence VHX 900F digital microscope was used, which thanks to the movable optical system, enables to observe the samples at different angles. Measurements were taken at the following magnifications: 10x, 20x and 50x, 100x and 500x. The original samples were tested as well as these after the first and second UV irradiation cycle were studied. In addition, in order to emphasize the changes on the surfaces of the tested specimens and to assess the depth at which degradation occurs, the red DIFFU-THERM penetrant was used. This substance that is applied in flaw detection in welded joints studies, facilitates visualisation of even minor surface defects thanks to its penetrating deep into the material.

The gloss test was carried out using an Elcometer 406 glossmeter. Measurements were taken after the ageing process and on reference samples at five locations on each specimen.

In turn, the structure of polymer materials was assessed with the use of the differential scanning calorimetry (DSC) method, which allows to observe and measure thermal effects accompanying the phenomena occurring in the tested samples. This technique draws upon the difference in the flow of heat fluxes $\left(\Phi_{\mathrm{m}}\right)$ between the furnace and the test substance $\left(\Phi_{\mathrm{S}}\right)$, and between the furnace and the reference sample $\left(\Phi_{R}\right)$ under the influence of the set temperature:

$$
\Phi_{m}=\Phi_{S}-\Phi_{R}
$$

Thanks to DSC tests, it is possible to determine, including: the degree of crystallinity, melting and crystallisation temperature, glass transition temperature and others. Studies were carried out on a 214 Polyma NETZSCH DSC apparatus, which uses the method of measuring the heat flux. An empty crucible and crucible with a prepared sample are placed on a disk with multiple thermocouples and then the changes in heat flow are recorded. The total amount of transferred heat $(\mathrm{Q})$ corresponds to the time associated with the heat flow rate: 


$$
Q=\int \frac{d Q}{d t} d t
$$

The heat flow rate is the amount of heat transferred per unit of time $(\mathrm{dQ} / \mathrm{dt})$, expressed in watts $(\mathrm{W})$ and milliwatts $(\mathrm{mW})$. In turn, the content of the crystalline phase $\left(\alpha_{\mathrm{j}}\right)$ is determined from the following formula:

$$
\alpha_{j}=\frac{\Delta H_{j}}{\Delta H_{t o t, T}} x 100 \%
$$

where:

$\Delta \mathrm{H}_{\mathrm{j}}$ - enthalpy of sample melting in $\mathrm{J} / \mathrm{g}$ determined from a thermogram,

$\Delta \mathrm{H}_{\mathrm{tot}, \mathrm{T}}$ - theoretical enthalpy of melting completely crystalline polymer.

The tests were performed for non-aged (reference) samples and samples aged in the UV chamber. Here it should be mentioned that, the largest structural changes were observed in the surface layer, hence the DSC studies used this part of the tested samples where the impact of radiation and thus the degradation changes were the largest. Measurements were taken at a heating rate of $10 \mathrm{~K} / \mathrm{min}$, in accordance with PN-EN ISO 11357 standard. The obtained results were developed in the Proteus Analysis program.

\section{Results and discussions}

Observation of the surface of samples subjected to UV ageing shows that it has a negative impact on the surface layers of the tested materials and that these processes occur in these materials with different dynamics. The differences also relate to the nature of surface changes and the depth of their propagation in the tested sample. Figures 1-6 present the results of tests before and after ageing with UV rays at x100 and $x 500$ magnification, along with the spatial representation of the surface.

In the case of samples from semi-crystalline materials, significant changes can be observed on the surface of the tested specimens that are already visible to the naked eye.

Samples made of PP30T (Figure 1) are not only distinguished by a significant colour change, but also by numerous material losses on the entire surface of the samples, whereby the exposure time increases, the effects of degradation are more intense. At 500x magnification, numerous cracks with clearly visible particles of exposed talc can be seen. In turn, on the spatial projection of the sample surface (Figure 2), it may be seen that the changes do not only apply to the surface, but also affect the depth of the material.

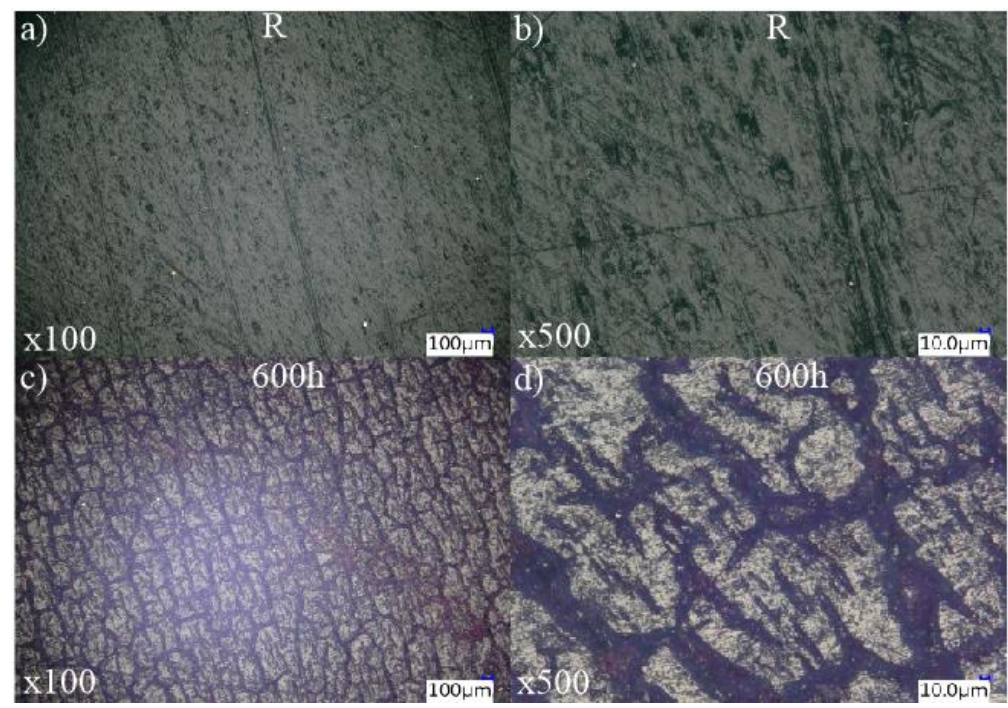

Figure 1. Surfaces of PP30T specimens samples: a) primary sample at a100x magnification, b) primary sample t 500x magnification, c) sample after $600 \mathrm{~h} \mathrm{UV}$ at 100x magnification, d) sample after $600 \mathrm{~h} \mathrm{UV}$ at 500x magnification 


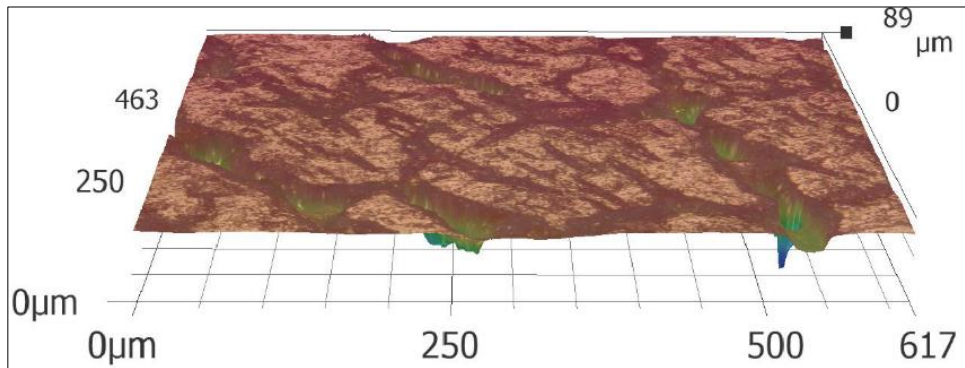

Figure 2. The spatial representation of the surface of the sample PP30T UV after ageing

UV ageing caused the formation of cracks on the entire surface of the samples made of poly(ethylene), as shown in Figure 3. In process of exposure time, more and more of them appeared and were increasingly visible. This - in turn - caused a general decrease in the strength properties of the tested material, due to the greater susceptibility to cracking, which was discovered organoleptically.

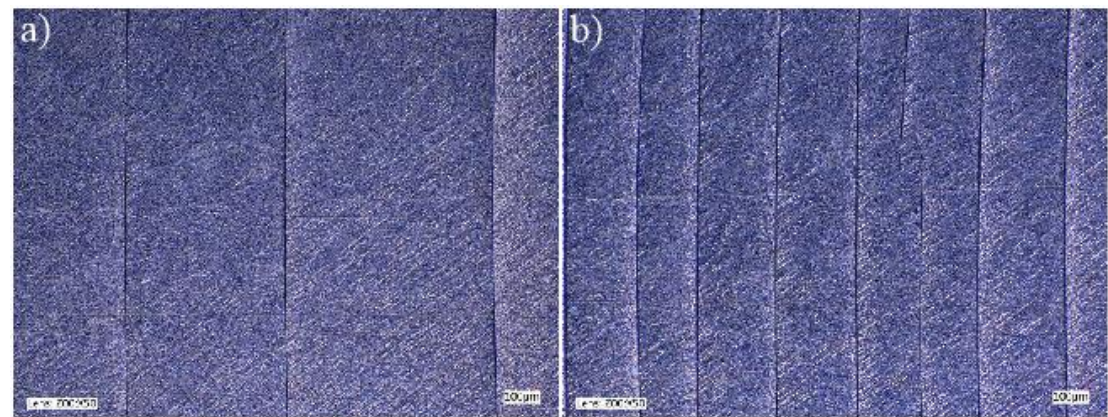

Figure 3. Clearly visible propagation of cracks on the surface of PE samples at x50 magnification: a) after $300 \mathrm{~h}$ UV irradiation,

b) after $600 \mathrm{~h}$ UV irradiation

In samples made of PE, the nature of the surface changes is quite different than for specimens made of talc-filled PP. Parallel cracks oriented perpendicular to the flow front of the material in the injection mould are only visible on the entire surface (Figure 4) of the samples. The longer radiation time only caused concentration of the formed cracks, which nature indicates probably the influence of the flow and pressure drop in the filling process and the clamping phase. The spatial representation of the aged surface does not show any significant differences in the heights of the highest and lowest areas, which may be clearly seen during observing the cross-sections.

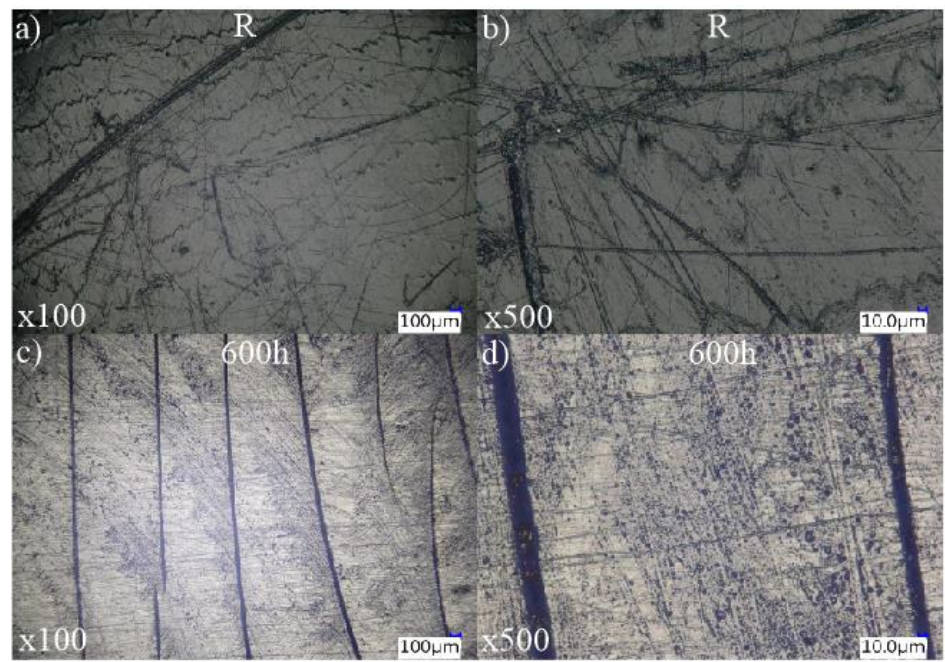

Figure 4. Surfaces of PE specimens samples: a) primary sample at 100x magnification, b)

primary sample at $500 \mathrm{x}$ magnification, c) sample after $600 \mathrm{~h} \mathrm{UV}$ at 100x magnification, d) sample after $600 \mathrm{~h}$ UV at 500x magnification 
Samples made of poly(acetal) POM (Figure 5-6) are characterized by the complete loss of gloss. The surface of original samples is characterized by the presence of numerous bubbles that disappear under the influence of UV rays. In process of exposure time, their surface layer changes and the phenomenon of chalking may be observed on the surface. At higher magnifications, numerous irregular cracks are visible on the surface of the tested samples. In these gaps, loose particles of material separated from the native material may be observed, which were formed as a result of the degradation processes (Figure 6).

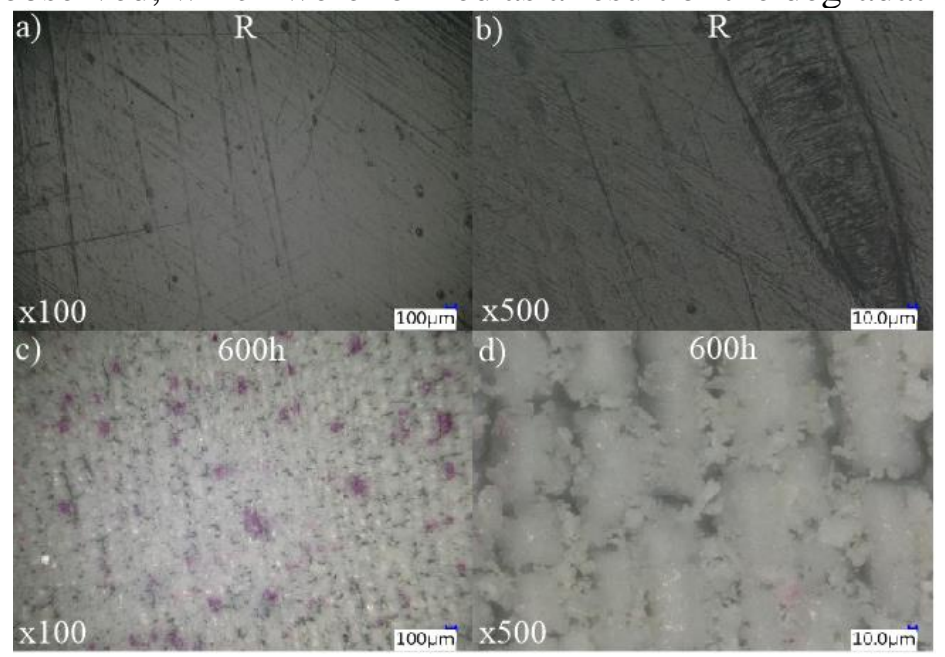

Figure 5. Surfaces of POM specimens samples: a) primary

sample at 100x magnification, b) primary sample at

500x magnification, c) sample after $600 \mathrm{~h}$ UV at 100x magnification

d) sample after $600 \mathrm{~h} \mathrm{UV}$ at 500x magnification

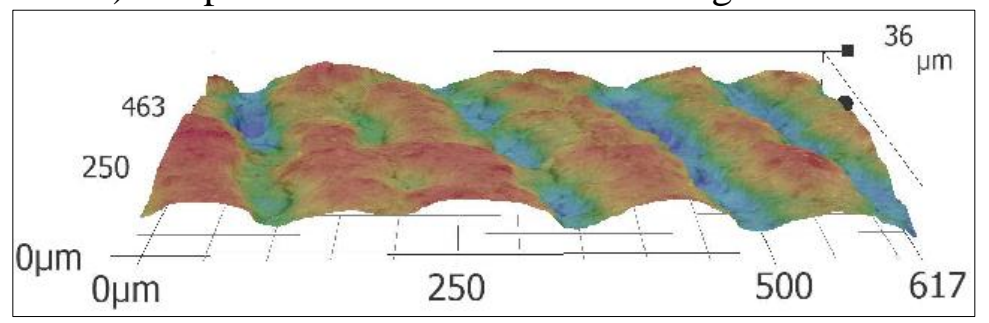

Figure 6. The spatial representation of the surface of the sample POM UV after ageing

Cross-sections of samples made of semi-crystalline materials (Figure 7) allow for more accurate measurements of the thickness of the degraded layer and the intensity of its impact on surface layers. These research shows that POM is the least susceptible to degradation - the average thickness of the degraded layer was $125,9 \mu \mathrm{m}$. In turn, the most easily degradable material is poly(ethylene) - the thickness of this layer totalled $311,5 \mu \mathrm{m}$. In the case of polypropylene with the addition of talc the thickness of the degraded layer amounted to $271,2 \mu \mathrm{m}$. The difference between these materials in the thickness of the degraded layer hovered $280 \mu \mathrm{m}$.

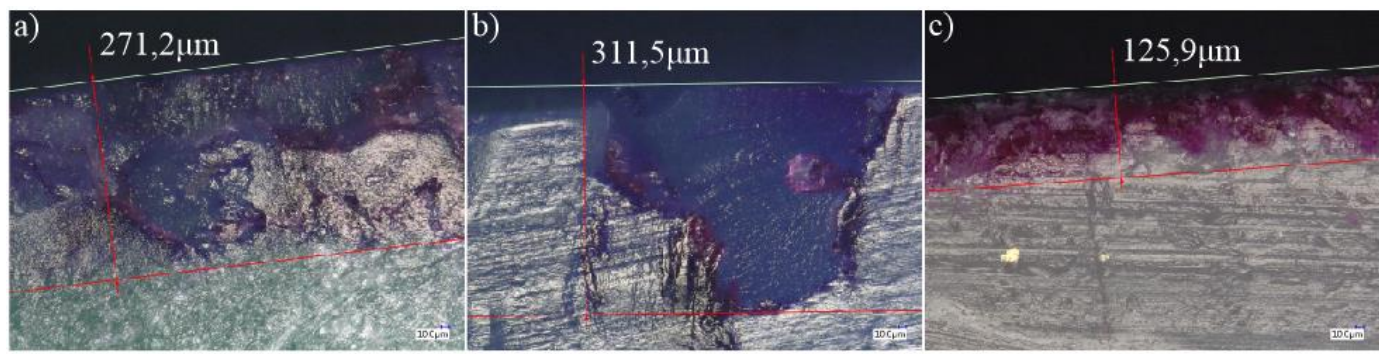

Figure 7. The cross-sections of samples of semi-crystalline materials with a marked layer of UV radiation: a) PP30T, b) PE, c) POM 
An important factor in the processes of degradation of the surface layer of polymers is the gloss change, which from the point of view of colour perception, affects the intensity of light scattering. Table 2 presents the averaged values of gloss measurement with an angle of light on the surface of $60^{\circ}$ for primary and aged samples. The highest gloss value of non-aged samples was observed for poly (acetal) POM, while the lowest for poly (propylene) PP30T, which may be due to the addition of talc. In the case of semi-crystalline materials, a general decrease in gloss may be observed under the influence of UV rays, whereby the largest decrease was recorded for POM, while the smallest one for PE.

Table 2. Averaged gloss measurement values at $60^{\circ}$ angle of light

\begin{tabular}{cccc}
\hline & \multicolumn{2}{c}{ Averaged gloss values, $\mathbf{G} \mathbf{U}^{\circ}$ Gloss $\mathbf{U n i t}$} & $\Delta \mathbf{G U}^{\circ}$ \\
\cline { 2 - 4 } Material & $\begin{array}{c}\text { Primary sample, } \\
\text { GU\% standard deviation }\end{array}$ & $\begin{array}{c}\text { The sample subjected to 600 h } \mathbf{U V} \\
\text { irradiation process, GU } / \text { standard } \\
\text { deviation }\end{array}$ & $\begin{array}{c}\text { Percentage change } \\
\text { in gloss, \% }\end{array}$ \\
\hline POM & $54.1 / 0.85$ & $2.4 / 0.14$ & 95.57 \\
\hline PP30T & $18.5 / 0.99$ & $9.4 / 0.85$ & 49.19 \\
\hline PE & $44 / 3.11$ & $37.75 / 2.76$ & 14.20 \\
\hline
\end{tabular}

The DSC method was used to analyse changes in thermal properties of the degraded layer, whereby in order to analyse the changes in the properties of the degraded surface relative to the reference samples, the mechanical loose (degraded) surface of the samples was removed and submitted to examination. Figures $8 \div 10$ show DSC thermograms of samples before and after ageing. A second heating process was used to remove the thermal history of the samples tested and to remove the impact of their processing. Two graphs are presented on the thermograms (the first from the top of the original samples, while the second below for samples subjected to the process of irradiation with $600 \mathrm{~h}$ of UV rays).

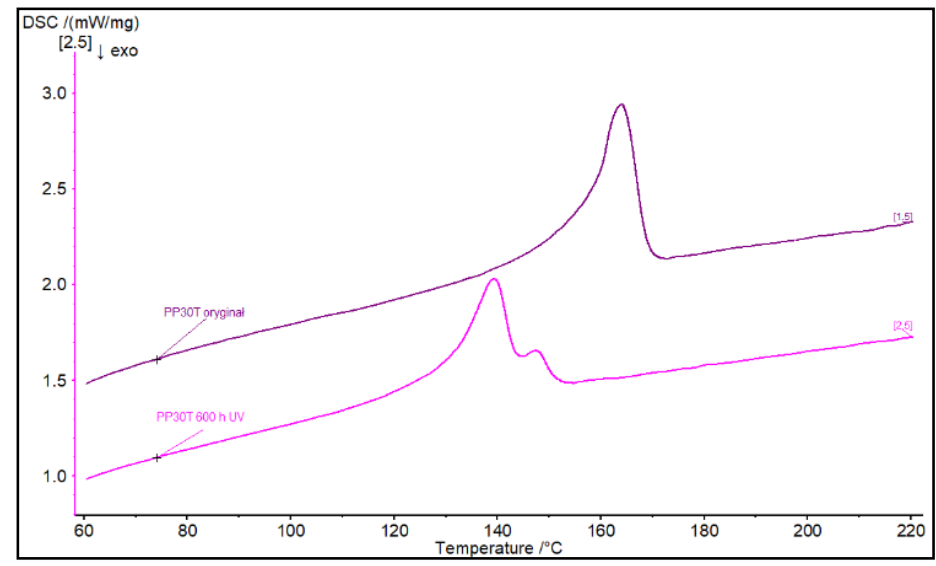

Figure 8. DSC

thermograms of PP30T

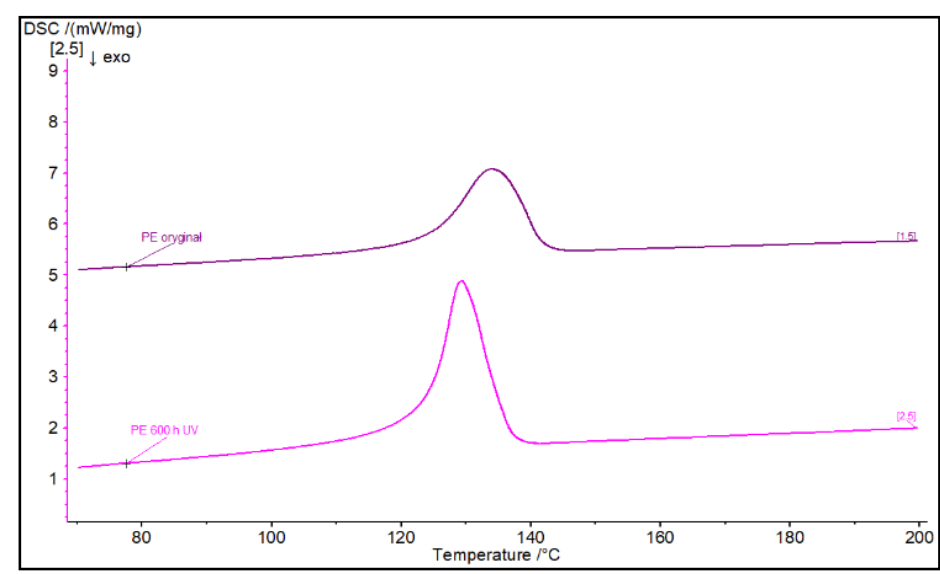

Figure 9. DSC thermograms of PE 


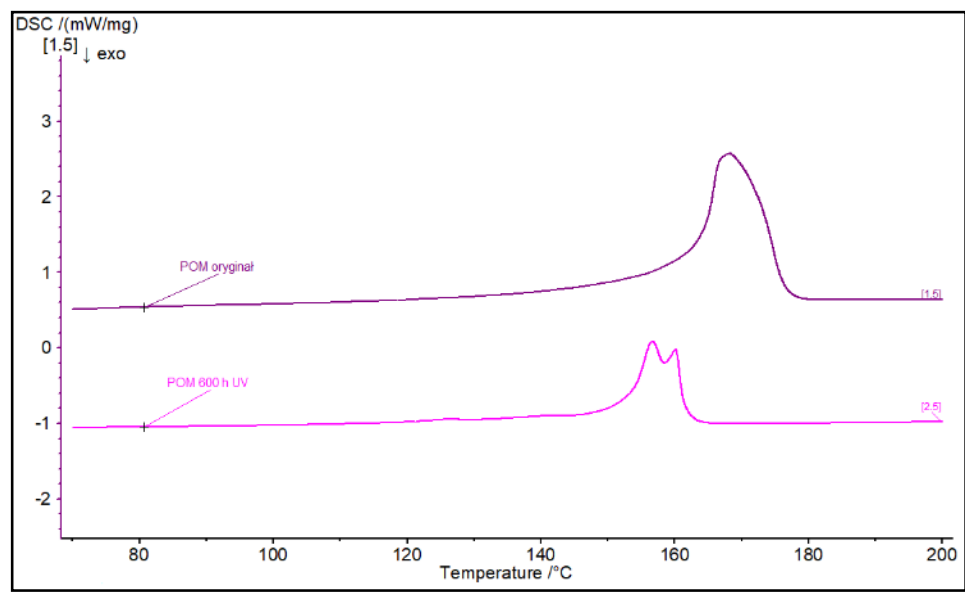

Figure 10. DSC thermograms of POM

In turn, in Table 3 the results of DSC tests were correlated. It shows that a decrease in the value of the melting enthalpy after the accelerated ageing was observed for all studied materials. Based on these values, it is possible to calculate the degree of crystallinity of the tested materials. The largest decrease in melting enthalpy and the degree of crystallinity was observed for samples made of POM, while the smallest ones for PE specimens. In both poly(ethylene) and poly(acetal) the melting range was narrowed down under the influence of UV radiation. On the other hand, a slight decrease in comparison with primary samples was recorded for polypropylene with the addition of talc. Significant shifts in melting and crystallisation temperatures were observed for POM and PP30. This phenomenon could be caused by the shortening of the macromolecule length (change in the molecular weight distribution of the tested samples). In addition, in the case of these samples, the presence of an additional peak was observed. For samples made of PE, a slight drop in the melting point and increase in crystallisation temperature were noted.

Table 3. Results of semi-crystalline samples obtained by DSC

\begin{tabular}{ccccccc}
\hline Material & $\begin{array}{c}\text { Melting point } \\
\text { range, }{ }^{\circ} \mathbf{C}\end{array}$ & $\begin{array}{c}\text { The } \\
\text { temperature at } \\
\text { which melting } \\
\text { occurs fastest, } \\
{ }^{\circ} \mathbf{C}\end{array}$ & $\begin{array}{c}\text { Enthalpy of } \\
\text { melting, J/g }\end{array}$ & $\begin{array}{c}\text { The degree of } \\
\text { crystallinity, \% }\end{array}$ & $\begin{array}{c}\text { Crystallisation } \\
\text { temperature, }{ }^{\circ} \mathbf{C}\end{array}$ \\
\hline \multirow{2}{*}{ PP30T } & $\begin{array}{c}\text { Primary } \\
\text { sample }\end{array}$ & $158.3 \div 168.7$ & 164.0 & 54.39 & 26.02 & 120.6 \\
\cline { 2 - 7 } & $\begin{array}{c}\text { UV aged } \\
\text { sample }\end{array}$ & $131.5 \div 141.7$ & $\begin{array}{c}139.3 \\
147.3\end{array}$ & 44.19 & 21.14 & 111.5 \\
\hline \multirow{2}{*}{ PE } & $\begin{array}{c}\text { Primary } \\
\text { sample }\end{array}$ & $124.8 \div 141.6$ & 133.9 & 198.1 & 67.60 & 113.6 \\
\cline { 2 - 7 } POM & $\begin{array}{c}\text { UV aged } \\
\text { sample }\end{array}$ & $124.1 \div 136.1$ & 129.3 & 192.7 & 65.78 & 143.9 \\
\hline \multirow{2}{*}{$\begin{array}{c}\text { Primary } \\
\text { sample }\end{array}$} & $\begin{array}{c}\text { UV aged } \\
\text { sample }\end{array}$ & $163.5 \div 176.5$ & 168.2 & 156.1 & 47.90 & 139.7 \\
\hline
\end{tabular}

During accelerated UV ageing various types of structural changes occurred in the tested polymer materials and their phase composition changed - an increase in the proportion of the amorphous phase and a decrease in the crystalline phase was observed. The degradation of semi-crystalline materials most likely resulted in shorter, irregular sections of macromolecules, which weakened the nucleation process. 


\section{Conclusions}

The study of accelerated ageing of polymeric materials in various physicochemical conditions enables to determinate the probability of changes in their properties in the process of time of degrading factors's effects.

The analysis of the conducted tests allows to state that UV radiation has a significant impact on the surface changes of polymer materials. Studies on the microscope show that it contributes to the formation of numerous damages to the surface layer of the tested materials - micro-cracks, surface defects or chalking. Changes in the surface layer of samples made of poly(acetal), poly(ethylene) and poly(propylene) are visible to the naked eye after a short time.

The spatial representation of the surface of aged samples of semi-crystalline materials shows significant differences in the nature of surface degradation processes. For example, PP samples filled with talc exhibit a much more intense development of the degraded surface, which in turn affects the dynamics of the processes of destruction of the surface layer. A very unfavourable phenomenon observed for POM material is the formation of a significant number of cracks and deep craters located at short distances. This may cause a very disadvantageous phenomenon of increasing the active surface of the impact of environmental factors, including liquids, which together with UV radiation may significantly accelerate the destruction of the material.

Research sections of the specimens subjected to ageing allow to assess the depth of the impact of radiation into the sample. The largest changes in the surface layer were observed for poly(ethylene) samples, while the use of a penetrant facilitates easier determination of the degraded surface layer of the tested materials.

UV ageing reduces the gloss of semi-crystalline materials. The largest changes in gloss were observed for POM and amounted to $95.57 \%$ of the initial value.

Analysis of the obtained DSC results enables the assessment of changes in the structure properties of the tested materials, which informs that they occur most quickly within a small thickness of the surface layer. Studies have shown that after ageing, the melting enthalpy value and the degree of crystallinity decrease, while the melting range narrows down.

During the action of UV rays on samples made from PP30T, PE and POM, it is most likely that their phase composition changed - namely the proportion of the amorphous phase to the crystalline phase increased in relation to the primary samples. The accelerated ageing process probably caused the shortening of some macromolecules (especially in the surface layers of the tested samples).

In the conducted research, it is worth paying attention to the nature of the changes appearing in individual materials. Surface changes during the full ageing period may contribute to faster propagation of changes in the surface layer and thus even more intensify the ageing process.

An important factor in the accelerated tests by laboratory methods is also the reference of their results to analogous tests in natural conditions, where in addition to the impact of UV radiation to a wider extent, it is also dealt with changes in temperature, humidity or the impact of rainfall and other chemicals founding the atmosphere.

Future research will be expanded by comparing them with the ageing process in natural conditions. The presence of colouring agents may have delayed the ageing process. Their role may form the basis for further research.

\section{References}

1.KOSZKUL J., SUBERLAK O., „Fundamentals of physicochemistry and polymer properties”, Częstochowa University of Technology Publishing House, Częstochowa 2004 (in Polish).

2.***PN-EN ISO 175:2010 Tworzywa sztuczne - Metody badań stosowane do określenia skutków zanurzenia w ciekłych chemikaliach.

3.BOCIĄGA E., TRZASKALSKA M., Processing conditions vs. mechanical properties of mouldings made of coloured copolymer ABS, Plastics processing, 172, 2016, p. 190-199. 
4.TRZASKALSKA M., PALUTKIEWICZ P., BOCIĄGA E., Mechanical properties of colored acrylonitrile-butadiene-styrene injection molded parts, Polymers, 63, 2018, p. 791-798.

https://dx.doi.org/10.14314/polimery.2018.11.7

5.WHITE J.R., Polymer ageing: physics, chemistry or engineering? Time to reflect, Compets Rendus Chimie, 11, 2006, p. 1396.

http://10.1016/j.crci.2006.07.008

6.BRONDSTED P., ANDERSEN S.I., LILHOLT H., Mechanics of Composites Materials, 32, 1996, p. 21.

7.HUANG G., ROTEM A., Materials and Design, 28, 2007, p. 1647.

8.IMIELIŃSKA K., WOJTYRA R., Water absorption behaviour of vinyl ester laminates reinforced with aramid and glass fibres, Composites, 7, 2003, p. 192-197.

9.KATUNIN A., ,Thermal degradation of polymer laminates”, Publisher of the Institute of Sustainable Technologies of the National Research Institute, Radom 2012 (in Polish).

10.MARTIN R., ,Ageing of composites”, Woodhead Publishing Limited, Cambridge 2008.

11.MOUZAKIS D.E., ZOGA H., GALIOTIS C., Composites Part B, 39, 2008, p. 467.

12.SKOMRA M., FIC G., BACZA W., Using methods of the artificial intelligence in the computer simulation of polymers degradation, Plastics processing, 164, 2015, p. 166-170.

13.JACHOWICZ T., KRZYŻAK A., The effect of natural ageing on selected properties of polyethylene pipes, MOTROL, 11, 2009, p. 70-76.

14.JACHOWICZ T., SIKORA R., Methods of forecasting of the changes of polymeric products properties, Polymers, 51, 2006, p. 177-185.

15.KOTNAROWSKA D., ,The destruction of polymer coatings under the influence of operational factors", UTH Publishing House in Radom, Radom 2013.

16.KACZMAREK H., KOSMALSKA D., MALINOWSKI R., Advances in studies of thermal degradation of polymeric materialsPart I. Literature studies, Polymers, 64, 2019, p. 239-250.

https://dx.doi.org/10.14314/polimery.2019.4.1

17.MASŁOWSKI M., ZABORSKI M., Effect of thermooxidative and photooxidative ageing processes on mechanical properties of magnetorheological elastomer composites Polymers, 60, 2015, p. 264-271. https://dx.doi.org/10.14314/polimery.2015.264

18.RABEK J. F., Modern knowledge of polymers, PWN Scientific Publishing House, Warszawa 2008 (in Polish).

19.WRÓBEL G., SZYMICZEK M., ROJEK M., Thermal characteristics in the diagnosis of fatigue ageing characteristics of composite cylindrical shells, Plastics processing, 157, 2014, p.110-115.

20.ROJEK M., „Methodology of diagnostic tests of layered composite materials with a polymer matrix”, International OCSCO World Press, Gliwice 2011 (in Polish).

21. KOTNAROWSKA D., „Protective coatings”, Radom University of Technology Publishing House, Radom 2010 (in Polish).

22.WAWRZASZEK R., WAWRZASZEK U., Coupled methods of thermal analysis in research photodegradation of plastics, Plastics in Industry, 4, 2017, p. 39.

23.***https://www.slideshare.net/uk29652/polymer-weathering-60107071 (access date: 13. 04. 2019)

24.OLEWNIK-KRUSZKOWSKA E., Effect of a compatibilizong agent on thermal properties of polylactide-based composites exposed to UVC radiation, Plastics processing, 170, 2016, p. 84-90.

25.MAZIK K., POSTAWA P., WOJCIECHOWSKA M., Effect of chemical agents on the resistance of some plastic polymer. Part 1, Preparation of samples, test photoelastic, Plastics processing, 152, 2013, p. 115-121.

26.MAZIK K., POSTAWA P., WOJCIECHOWSKA M., Effect of chemical agents on the resistance of some plastic polymer. Part 2, Plastics processing, 154, 2013, p. 440-445.

27.SOBKÓW D., CZAJA K., Influence of accelerated ageing conditions on the process of polyolefines degradation, Polymers, 48, 2003, p. 627-632. 
28.GNATOWSKI A., Studies on the influence of soaking and ultraviolet irradiation ageing on the structure of compatibilized PP/PA 6 mixtures, Polymers, 56, 2011, p. 121-128.

29.GNATOWSKI A., CHYRA M., BARANOWSKI W., Analysis of thermal properties and structure of pipes of polyethylene after ageing, Plastics processing, 152, 2013, p. 97-102.

30.WĄSICKI A., KOŚCIUSZKO A., DSC investigations of the surface layer of an aged polypropylene/ wood composite, Polymers, 56, 2011, p. 401-404.

31.LATOS M., MASEK A., ZABORSKI M., Photodegradation of polymeric materials, Plastics processing, 178, 2017, p. 358-363.

32.BARCZEWSKI M., ANDRZEJEWSKI D., MATYKIEWICZ A., KRYGIER A., KLOZIŃSKI A., Influence of accelerated weathering on mechanical and thermomechanical properties of poly(lactic acid) composites with natural waste filler, Polymers, 64, 2019, p. 119-126.

https://dx.doi.org/10.14314/polimery.2019.2.5

33.GAUTHIER E., NIKOLIĆ M., TRUSS R., LAYCOCK B., HALLEY P., Effect of soil environment on the photo-degradation of polyethylene films, Journal of Applied Polymer Science, 2015.

https://doi.org/10.1002/app.42558

$\overline{\text { Manuscript received: } 30.03 .2020}$ 